\title{
A Facile Synthesis and Optical Properties of Bundle-Shaped $\mathrm{TbPO}_{4} \cdot \mathrm{H}_{2} \mathrm{O}$ Nanorods
}

\author{
Dan Yue, ${ }^{1,2}$ Wen Luo, ${ }^{2}$ Wei Lu, ${ }^{3}$ Ruiyong Wang, ${ }^{1}$ Chunyang Li, ${ }^{2}$ \\ Jiazhong Chang, ${ }^{2}$ and Zhenling Wang ${ }^{2}$ \\ ${ }^{1}$ The College of Chemistry and Molecular Engineering, Zhengzhou University, Zhengzhou 450001, China \\ ${ }^{2}$ The Key Laboratory of Rare Earth Functional Materials and Applications, Zhoukou Normal University, Zhoukou 466001, China \\ ${ }^{3}$ Department of Applied Physics and Materials Research Center, The Hong Kong Polytechnic University, Hong Kong
}

Correspondence should be addressed to Ruiyong Wang; wangry@zzu.edu.cn and Zhenling Wang; wangzhenling@zknu.edu.cn

Received 14 November 2013; Accepted 1 December 2013

Academic Editor: Jianhua Hao

Copyright (C) 2013 Dan Yue et al. This is an open access article distributed under the Creative Commons Attribution License, which permits unrestricted use, distribution, and reproduction in any medium, provided the original work is properly cited.

\begin{abstract}
Bundle-shaped $\mathrm{TbPO}_{4} \cdot \mathrm{H}_{2} \mathrm{O}$ nanorods have been prepared by a facile hydrothermal technique and characterized by XRD, SEM, TEM, UV-Vis diffuse reflectance spectrum (DRS), photoluminescence (PL) spectrum, and lifetime. The results indicate that the obtained sample has hexagonal structure of $\mathrm{TbPO}_{4} \cdot \mathrm{H}_{2} \mathrm{O}$ and is composed of nanorods bundles which is assembled from many single crystalline nanorods with the diameter of around $45 \mathrm{~nm}$ and the length of $2.3 \mu \mathrm{m}$. The growth of the single crystalline nanorod is along the (001) plane direction. Under the UV light irradiation, $\mathrm{TbPO}_{4} \cdot \mathrm{H}_{2} \mathrm{O}$ nanorods bundles exhibit bright green emission corresponding to the ${ }^{5} \mathrm{D}_{4} \rightarrow{ }^{7} \mathrm{~F}_{J}(J=6,5,4,3)$ transitions of the $\mathrm{Tb}^{3+}$ ions, and the lifetime is determined to be about $0.24 \mathrm{~ms}$.
\end{abstract}

\section{Introduction}

In recent years, inorganic nanostructures with well-defined shapes and sizes have attracted growing attention because of their unique size- and shape-dependent properties [1-3]. Among many kinds of nanostructured materials, lanthanide orthophosphates $\left(\mathrm{LnPO}_{4}\right)$ with uniform size and various morphologies have been prepared by some mild and controllable methods $[4,5]$ and attracted great interest because of their unique properties including very low solubility in water (The solubility product constant, $p \mathrm{~K}_{\mathrm{sol}}=25-27$ ) [6], high thermal stability, high index of refraction, and high luminescent efficiency $[7,8]$. These materials have been used as active components in a wide range of applications such as phosphors, laser hosts, and biolabeling [912]. The chemical and optical properties of one-dimensional (1D) $\mathrm{LnPO}_{4}$ nanostructures (e.g., $\mathrm{CePO}_{4}: \mathrm{Tb}^{3+}$ nanowires, $\mathrm{LaPO}_{4}$ nanorods, $\mathrm{CePO}_{4}$ peanut-liked nanostructures, etc.) can be successfully tailored, which makes these materials have significant potential applications in fabricating the next generation of information storage, optoelectronic, sensing devices, and nanoscale devices [13-15].
As an important sort of lanthanide phosphates, $\mathrm{TbPO}_{4}$ has been investigated mainly focusing on its physical lowtemperature properties (magnetic properties, birefringence measurements, and mean-field calculations) in previous literatures $[16,17]$. Recently, much attention has been focused on the synthesis and properties of the $\mathrm{TbPO}_{4}$ with various morphologies. It is known that the hydrothermal technique is a common method in the field of material science. Using this technique, many materials with uniform morphology and satisfying crystallinity can be obtained at relatively low reaction temperature, usually without any further calcinations at high temperature $[18,19]$. For example, $\mathrm{TbPO}_{4}: \mathrm{Eu}^{3+}$ square-like particles were prepared by hydrothermal method with citric acid as the organic additive, and the reaction temperature is as low as $160^{\circ} \mathrm{C}$ [20]. As a contrast, $\mathrm{TbPO}_{4}$ hollow spheres can be obtained through solid state method when the annealing temperature is increased to $1150^{\circ} \mathrm{C}$ $[21,22]$. In this work, uniform $\mathrm{TbPO}_{4} \cdot \mathrm{H}_{2} \mathrm{O}$ bundle-shaped nanostructures composed of single crystalline nanorods were synthesized at $180^{\circ} \mathrm{C}$ through a facile hydrothermal technique and characterized by XRD, SEM, TEM DRS, PL spectra, and so forth. The possible mechanism leading to 


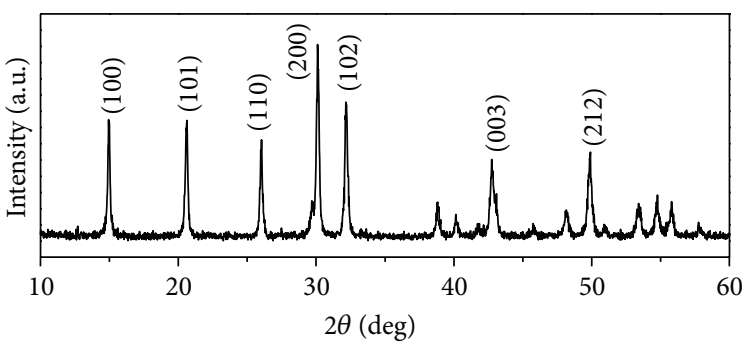

(a)

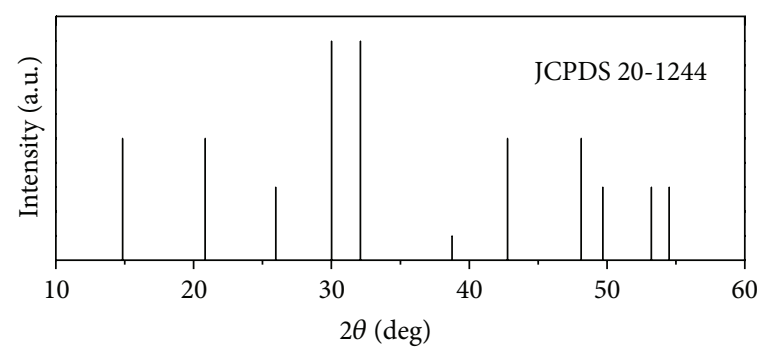

(b)

FIGURE 1: XRD patterns of bundle-shaped $\mathrm{TbPO}_{4} \cdot \mathrm{H}_{2} \mathrm{O}$ nanorods (a) and standard data of bulk $\mathrm{TbPO}_{4} \cdot \mathrm{H}_{2} \mathrm{O}((\mathrm{b})$, JCPDS card 20-1244).

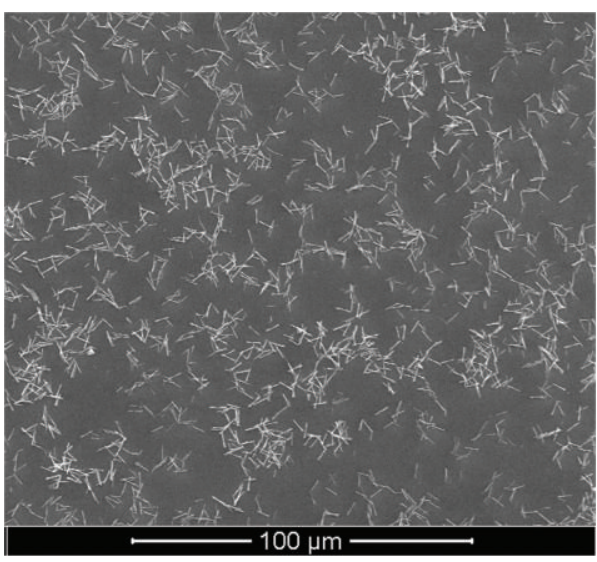

(a)

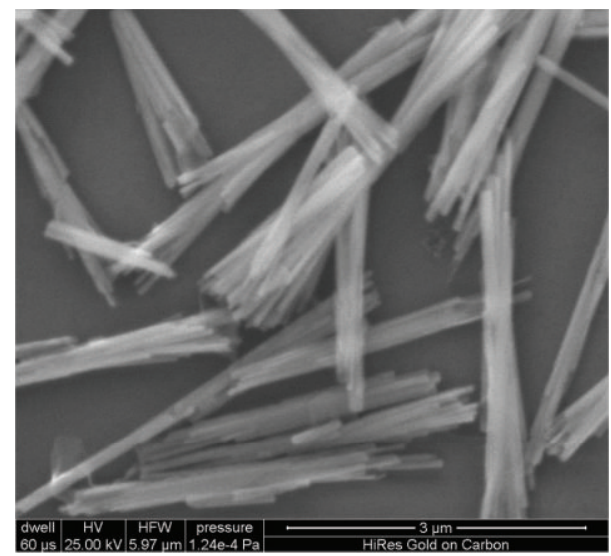

(b)

Figure 2: SEM images (a) and (b) of $\mathrm{TbPO}_{4} \cdot \mathrm{H}_{2} \mathrm{O}$ nanorods bundles.

bundle-shaped structures, phase structure, morphology, and optical properties were discussed in detail.

\section{Experimental Section}

2.1. Synthesis of Bundle-Shaped $\mathrm{TbPO}_{4} \cdot \mathrm{H}_{2} \mathrm{O}$ Nanorods. $\mathrm{Tb}_{4} \mathrm{O}_{7}(99.99 \%)$ and $\left(\mathrm{NH}_{4}\right)_{2} \mathrm{HPO}_{4}(\geq 98.5 \%)$ were used as starting materials without any further purification. $\mathrm{Tb}\left(\mathrm{NO}_{3}\right)_{3}$ was prepared by dissolving $\mathrm{Tb}_{4} \mathrm{O}_{7}$ in diluted nitric acid, and the water in the solutions was distilled off by heating. Bundle-shaped $\mathrm{TbPO}_{4} \cdot \mathrm{H}_{2} \mathrm{O}$ nanorods were prepared by hydrothermal technique. Typically, $2 \mathrm{mmol}$ of $\left(\mathrm{NH}_{4}\right)_{2} \mathrm{HPO}_{4}$ was added to $20 \mathrm{~mL}$ of $0.1 \mathrm{~mol} / \mathrm{L} \mathrm{Tb}\left(\mathrm{NO}_{3}\right)_{3}$ aqueous solution and the mixture was continuously stirred for $2 \mathrm{~h}$. The obtained suspension was then transferred into a Teflon bottle held in a stainless steel autoclave, which was sealed and hydrothermally treated at $180^{\circ} \mathrm{C}$ for $24 \mathrm{~h}$. After the autoclave was cooled to room temperature naturally, the precipitates were separated by centrifugation, washed with ethanol and distilled water twice, respectively, and dried at $70^{\circ} \mathrm{C}$ for $24 \mathrm{~h}$ to obtain the sample.

2.2. Characterization. Phase structure was characterized by a Bruker D8 Advance X-ray diffractometer (XRD) with $\mathrm{Cu}$ $\mathrm{K} \alpha$ radiation $(\lambda=0.15406 \mathrm{~nm})$. The accelerating voltage and emission current were $40 \mathrm{kV}$ and $40 \mathrm{~mA}$, respectively.
Morphology of the samples was observed using a scanning electron microscope (SEM, Quanta 200) with an acceleration voltage of $25 \mathrm{kV}$. The TEM image and selected area electron diffraction (SAED) pattern were obtained on a JEOL-2010 transmission electron microscope at an accelerating voltage of $200 \mathrm{kV}$. UV-Vis diffuse reflectance spectrum (DRS) was obtained using a UV/Vis Spectrophotometer (Lambda35, PerkinElmer) equipped with an integrating sphere attachment. Photoluminescence (PL) spectra and lifetime were recorded using an FLS920P Edinburgh Analytical Instrument apparatus equipped with a $450 \mathrm{~W}$ xenon lamp and a $\mu \mathrm{F} 900 \mathrm{H}$ high-energy microsecond flash lamp as the excitation sources.

\section{Results and Discussion}

3.1. Phase Structure and Morphology. Figure 1 shows the XRD patterns of bundle-shaped $\mathrm{TbPO}_{4} \cdot \mathrm{H}_{2} \mathrm{O}$ nanorods (Figure 1(a)) and standard data of $\mathrm{TbPO}_{4} \cdot \mathrm{H}_{2} \mathrm{O}$ powders (Figure 1(b)). It can be seen that all of the diffraction peaks of the bundle-shaped $\mathrm{TbPO}_{4} \cdot \mathrm{H}_{2} \mathrm{O}$ nanorods are in agreement with the standard data of hexagonal structure $\mathrm{TbPO}_{4} \cdot \mathrm{H}_{2} \mathrm{O}$ (JCPDS No. 20-1244), with the space group of $P 3_{1} 21$ (152). Figures 2(a) and 2(b) show the low- and high-magnification SEM images of $\mathrm{TbPO}_{4} \cdot \mathrm{H}_{2} \mathrm{O}$ nanorods bundles, respectively. It can be seen that these bundle-shaped 


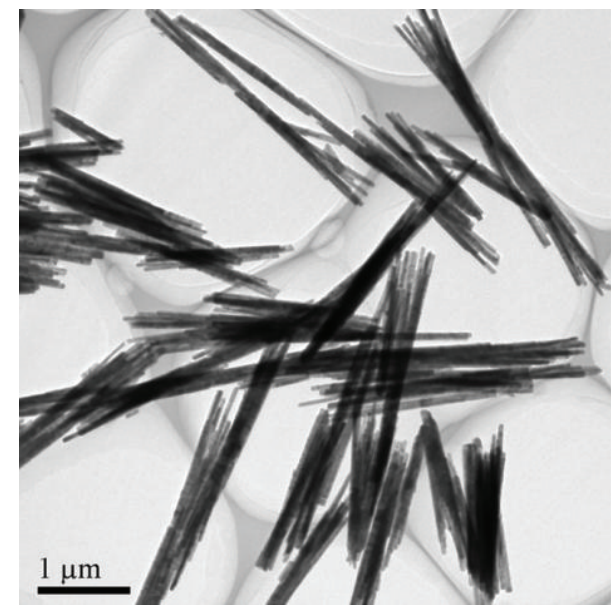

(a)

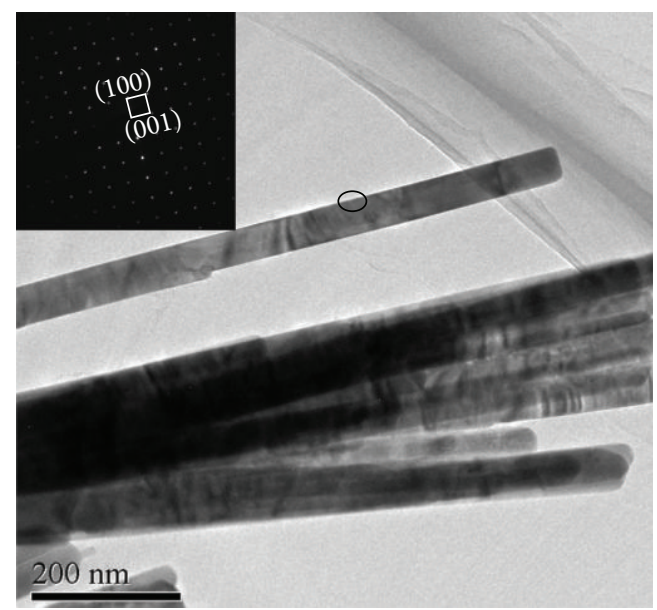

(b)

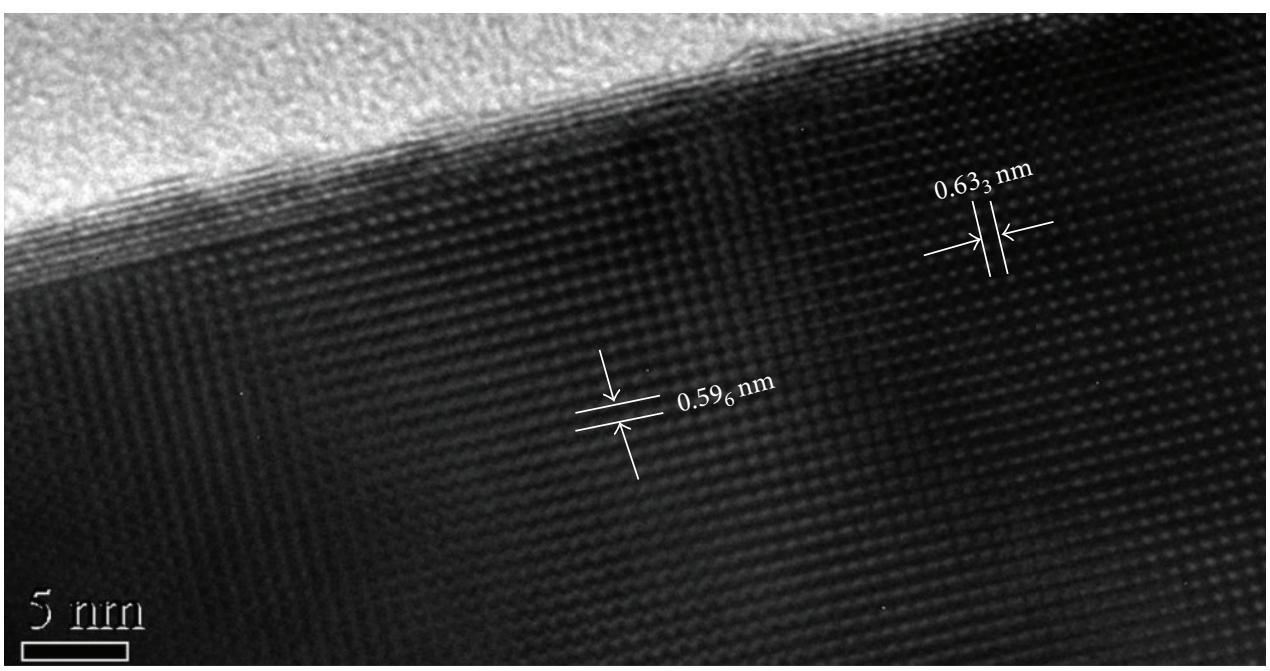

(c)

FIGURE 3: TEM images of bundle-shaped $\mathrm{TbPO}_{4} \cdot \mathrm{H}_{2} \mathrm{O}$ nanorods (a) and (b), SAED pattern (inset in (b)), and HRTEM image (c) of the single nanorod.

structures are homogeneous in the large field of vision (Figure 2(a)), the magnified image (Figure 2(b)) indicates that the bundle-shaped structures are actually composed of nanorods, and most of the nanorods are linked together by side-by-side conjunction.

To investigate the growth mechanism and microstructure of bundle-shaped structures in detail, the obtained sample was observed by the TEM and high resolution TEM (HRTEM) images equipped with selected area electron diffraction (SAED) pattern (Figure 3). It can be clearly seen from Figure 3(a) that the obtained sample is composed of bundle-shaped morphology, which is assembled by many $\mathrm{TbPO}_{4} \cdot \mathrm{H}_{2} \mathrm{O}$ nanorods with the diameter of $\sim 45 \mathrm{~nm}$ and the length of $\sim 2.3 \mu \mathrm{m}$. A high-magnified image of bundled nanorods (Figure 3(b)) indicates that these single crystalline nanorods as the primary construction unit are relatively uniform. The SAED pattern (Figure 3(b), inset) taken from the upper single nanorod can be indexed to the (100) and (001) planes of $\mathrm{TbPO}_{4} \cdot \mathrm{H}_{2} \mathrm{O}$ single crystalline with the hexagonal phase structure. These findings are consistent with the XRD result mentioned above. The HRTEM image (Figure 3(c)) of the single $\mathrm{TbPO}_{4} \cdot \mathrm{H}_{2} \mathrm{O}$ nanorod marked as an oval in Figure 3(b) displays singlecrystalline nature. The values of interplanar spacing of $\mathrm{TbPO}_{4} \cdot \mathrm{H}_{2} \mathrm{O}$ nanorod are 0.596 and $0.633 \mathrm{~nm}$, which is identical to the (100) and (001) facet distance of bulk $\mathrm{TbPO}_{4} \cdot \mathrm{H}_{2} \mathrm{O}$ powders, respectively. It can be seen that the growth direction of $\mathrm{TbPO}_{4} \cdot \mathrm{H}_{2} \mathrm{O}$ singlecrystalline nanorod is along (001) plane. According to the experimental results and analysis, the growth mechanism of $\mathrm{TbPO}_{4} \cdot \mathrm{H}_{2} \mathrm{O}$ nanorods bundles was proposed. Generally, $\mathrm{TbPO}_{4} \cdot \mathrm{H}_{2} \mathrm{O}$ tends to grow as $1 \mathrm{D}$ nanorods, which is possibly due to the $1 \mathrm{D}$ characteristics of the infinite linear chains of hexagonal-structured $\mathrm{TbPO}_{4}$ [7]. And then, the surface energy of these nanorods may change under the hydrothermal process [23], so these nanorods aggregates might be assembled and grown along the same direction 


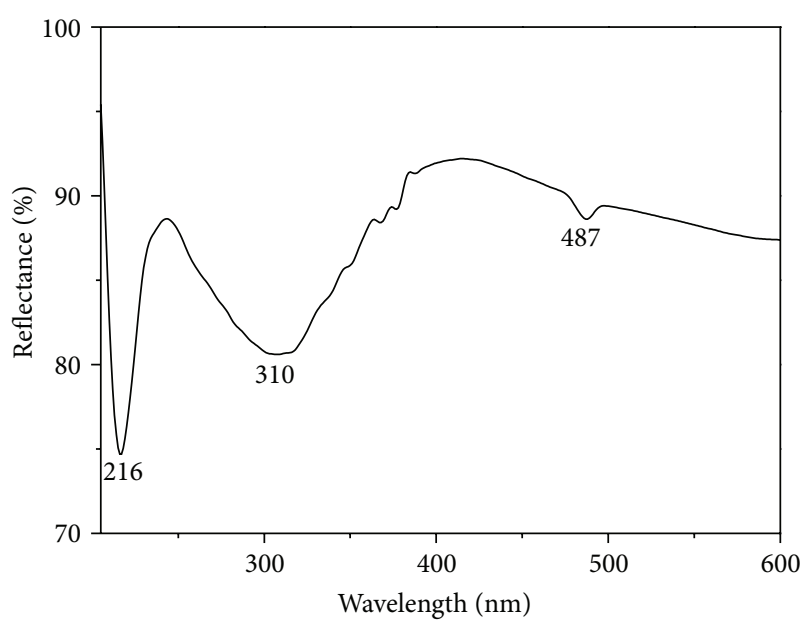

(a)

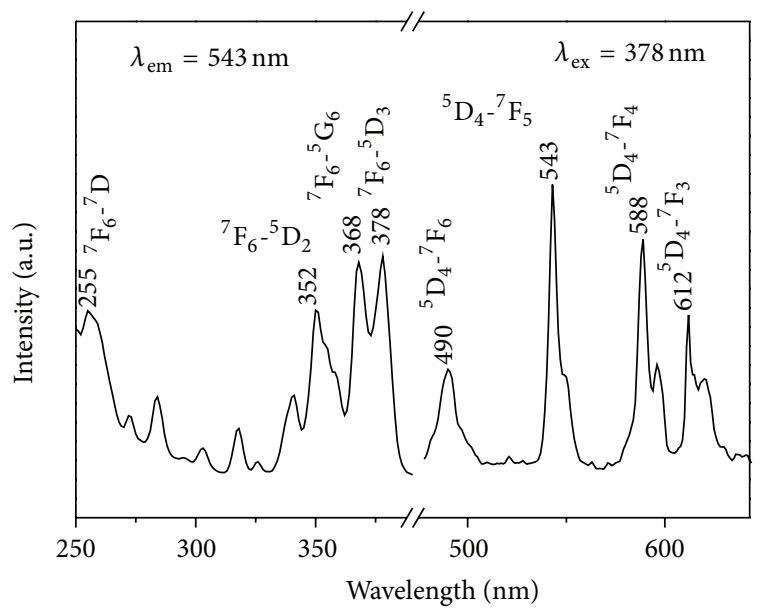

(b)

(c)

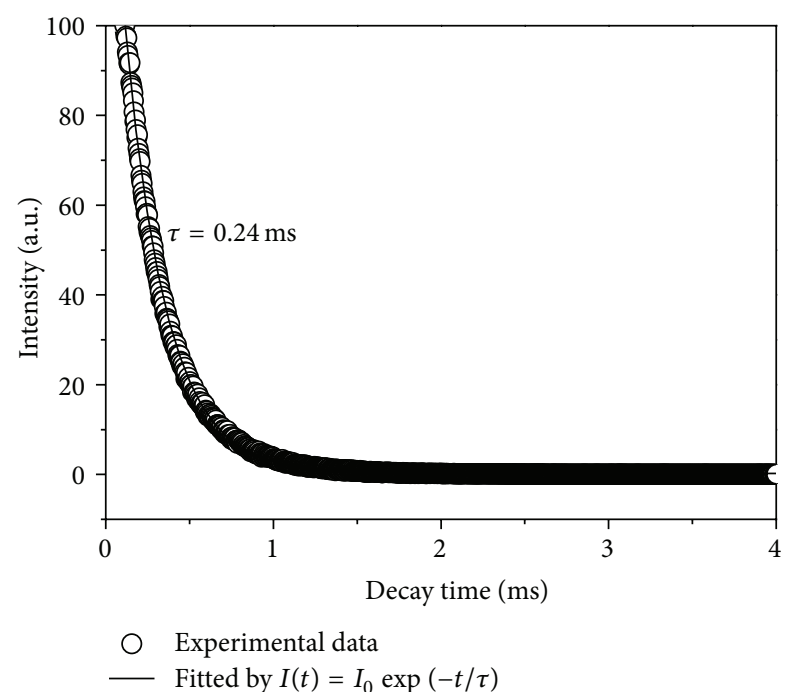

(d)

FIgURE 4: UV-Vis DRS (a), PL excitation (b), emission (c) spectra, and decay curve (d) of bundle-shaped $\mathrm{TbPO}_{4} \cdot \mathrm{H}_{2} \mathrm{O}$ nanorods.

(oriented attachment) to form bundle-shaped structures. The formation process of $\mathrm{TbPO}_{4} \cdot \mathrm{H}_{2} \mathrm{O}$ nanorods bundles is similar to that of $\operatorname{In}(\mathrm{OH})_{3}$ rod bundles [24].

3.2. Optical Properties. Figure 4(a) shows the UV-Vis DRS spectrum of $\mathrm{TbPO}_{4} \cdot \mathrm{H}_{2} \mathrm{O}$ nanorods bundles. The absorption peaks at 216 and $310 \mathrm{~nm}$ are due to the spin-allowed $4 \mathrm{f}-5 \mathrm{~d}$ transition and the spin-forbidden transition of the $\mathrm{Tb}^{3+}$ ions, respectively. The absorption peak at $487 \mathrm{~nm}$ is assigned to the transitions from the ground level ${ }^{7} \mathrm{~F}_{6}$ to the excited level ${ }^{5} \mathrm{D}_{4}$ of $\mathrm{Tb}^{3+}$ ion [25]. The excitation spectrum of $\mathrm{TbPO}_{4} \cdot \mathrm{H}_{2} \mathrm{O}$ nanorods bundles was obtained by monitoring the emission of $\mathrm{Tb}^{3+}$ due to ${ }^{5} \mathrm{D}_{4} \rightarrow{ }^{7} \mathrm{~F}_{5}$ transition at $543 \mathrm{~nm}$, as shown in Figure 4(b). It can be seen that the excitation peak at $255 \mathrm{~nm}$ is assigned to intra $4 \mathrm{f}^{8}$ transitions between the $4 \mathrm{f}^{7} 5 \mathrm{~d}^{1}$, and most of the excitation peaks can be clearly assigned $(352 \mathrm{~nm}$ : ${ }^{7} \mathrm{~F}_{6} \rightarrow{ }^{5} \mathrm{D}_{2} ; 368 \mathrm{nm:}:{ }^{7} \mathrm{~F}_{6} \rightarrow{ }^{5} \mathrm{G}_{6}$; and $\left.378 \mathrm{~nm}:{ }^{7} \mathrm{~F}_{6} \rightarrow{ }^{5} \mathrm{D}_{3}\right)$. Under the UV light irradiation $(378 \mathrm{~nm})$, the emission spectrum is composed of four well-resolved peaks at 490, 543, 588, and $612 \mathrm{~nm}$, which is corresponding to the ${ }^{5} \mathrm{D}_{4} \rightarrow{ }^{7} \mathrm{~F}_{J}(J=$ $6,5,4,3)$ transitions of $\mathrm{Tb}^{3+}$ ions as labeled in Figure 4(c). Figure $4(\mathrm{~d})$ shows the PL decay curves of $\mathrm{TbPO}_{4} \cdot \mathrm{H}_{2} \mathrm{O}$ nanorods bundles with the excitation wavelength $(378 \mathrm{~nm})$ and emission wavelength at $543 \mathrm{~nm}$. The PL decay curve for $\mathrm{Tb}^{3+}$ in the $\mathrm{TbPO}_{4} \cdot \mathrm{H}_{2} \mathrm{O}$ nanorods bundles can be well fitted into a single exponential function as $I(t)=I_{0} \exp (-t / \tau)(\tau$ is $1 / e$ lifetime of $\mathrm{Tb}^{3+}$ ion) [26]. The lifetime for $\mathrm{Tb}^{3+}$ in $\mathrm{TbPO}_{4} \cdot \mathrm{H}_{2} \mathrm{O}$ nanorods bundles is determined to be $0.24 \mathrm{~ms}$.

\section{Conclusion}

In summary, the bundle-shaped $\mathrm{TbPO}_{4} \cdot \mathrm{H}_{2} \mathrm{O}$ nanorods have been successfully prepared by the hydrothermal route. The reaction media are aqueous solution and free of any surfactants or templates, and the synthesis technique is simple and environmentally friendly. The bundle-shaped $\mathrm{TbPO}_{4} \cdot \mathrm{H}_{2} \mathrm{O}$ nanostructures are assembled by many single crystalline $\mathrm{TbPO}_{4} \cdot \mathrm{H}_{2} \mathrm{O}$ nanorods through side-by-side conjunction. 
And these nanorods bundles yield green emission attributed to the transitions from the ${ }^{5} \mathrm{D}_{4}$ to the ${ }^{7} \mathrm{~F}_{J}(J=6,5,4,3)$ energy levels of $\mathrm{Tb}^{3+}$, which makes these nanorods bundles have potential applications in many fields such as lighting and optoelectronic devices with nanometer dimensions.

\section{Acknowledgments}

This work is financially supported by the National Natural Science Foundation of China (nos. 21171179 and 21301200), the Excellent Youth Foundation of He'nan Scientific Committee (134100510018), and the Program for Science \& Technology Innovation Talents in University of Henan Province (no. 2011HASTIT030).

\section{References}

[1] G. Wang, Q. Peng, and Y. Li, "Lanthanide-doped nanocrystals: synthesis, optical-magnetic properties, and applications," Accounts of Chemical Research, vol. 44, no. 5, pp. 322-332, 2011.

[2] S. J. Zeng, M. K. Tsang, C. F. Chan, K. L. Wong, and J. H. Hao, "PEG modified $\mathrm{BaGdF}_{5}$ : $\mathrm{Yb} / \mathrm{Er}$ nanoprobes for multi-modal upconversion fluorescent, in vivo X-ray computed tomography and biomagnetic imaging," Biomaterials, vol. 33, pp. 9232-9238, 2012.

[3] S. Zeng, J. Xiao, Q. Yang, and J. Hao, "Bi-functional NaLuF4: $\mathrm{Gd}^{3+} / \mathrm{Yb}^{3+} / \mathrm{Tm}^{3+}$ nanocrystals: Structure controlled synthesis, near-infrared upconversion emission and tunable magnetic properties," Journal of Materials Chemistry, vol. 22, no. 19, pp. 9870-9874, 2012.

[4] C. X. Li, Z. Y. Hou, C. M. Zhang et al., "Controlled synthesis of $\mathrm{Ln}^{3+}(\mathrm{Ln}=\mathrm{Tb}, \mathrm{Eu}, \mathrm{Dy})$ and $\mathrm{V}^{5+}$ ion-doped $\mathrm{YPO}_{4}$ nano/microstructures with tunable luminescent colors," Chemistry of Materials, vol. 21, no. 19, pp. 4598-4607, 2009.

[5] R. Komban, R. Beckmann, S. Rode et al., "Surface modification of luminescent lanthanide phosphate nanorods with cationic "quat-primer" polymers," Langmuir, vol. 27, no. 16, pp. 1017410183, 2011.

[6] R. Yu, J. Bao, X. Yang et al., "Controlled synthesis of tetragonal terbium orthophosphate nanostructures through a solvothermal route," Research on Chemical Intermediates, vol. 37, no. 2-5, pp. 145-151, 2011.

[7] J. Bao, R. Yu, J. Zhang et al., "Controlled synthesis of terbium orthophosphate spindle-like hierarchical nanostructures with improved photoluminescence," European Journal of Inorganic Chemistry, no. 16, pp. 2388-2392, 2009.

[8] Y.-P. Fang, A.-W. Xu, R.-Q. Song et al., "Systematic synthesis and characterization of single-crystal lanthanide orthophosphate nanowires," Journal of the American Chemical Society, vol. 125, no. 51, pp. 16025-16034, 2003.

[9] W. Di, M.-G. Willinger, R. A. S. Ferreira, X. Ren, S. Lu, and N. Pinna, "Citric acid-assisted hydrothermal synthesis of luminescent TbPO 4:Eu nanocrystals: controlled morphology and tunable emission," Journal of Physical Chemistry C, vol. 112, no. 48, pp. 18815-18820, 2008.

[10] G. Phaomei, W. R. Singh, and R. S. Ningthoujam, "Solvent effect in monoclinic to hexagonal phase transformation in $\mathrm{LaPO}_{4}: \mathrm{RE}$ $\left(\mathrm{RE}=\mathrm{Dy}^{3+}, \mathrm{Sm}^{3+}\right)$ nanoparticles: photoluminescence study," Journal of Luminescence, vol. 131, no. 6, pp. 1164-1171, 2011.

[11] M. Ferhi, K. Horchani-Naifer, and M. Férid, "Hydrothermal synthesis and photoluminescence of the monophosphate
$\mathrm{LaPO}_{4}: \mathrm{Eu}(5 \%)$," Journal of Luminescence, vol. 128, no. 11, pp. $1777-1782,2008$.

[12] W. Bu, L. Zhang, Z. Hua, H. Chen, and J. Shi, "Synthesis and characterization of uniform spindle-shaped microarchitectures self-assembled from aligned single-crystalline nanowires of lanthanum phosphates," Crystal Growth and Design, vol. 7, no. 11, pp. 2305-2309, 2007.

[13] Y. Liu, Z.-G. Lu, Y.-Y. Gu, and W. Li, "Hydrothermal-assisted ion exchange synthesis and photoluminescence of $\mathrm{Li}^{+}$and $\mathrm{Eu}^{3+} \mathrm{CO}-$ doped $\mathrm{NaLa}\left(\mathrm{WO}_{4}\right)_{2}$ as near-UV type red phosphors," Journal of Luminescence, vol. 132, no. 5, pp. 1220-1225, 2012.

[14] Y.-F. Liu, Z.-P. Yang, and Q.-M. Yu, "Preparation and its luminescent properties of $\mathrm{AlPO}_{4}: \mathrm{Eu}^{3+}$ phosphor for w-LED applications," Journal of Alloys and Compounds, vol. 509, no. 21, pp. L199-L202, 2011.

[15] C. Wu and Y. Wang, "Hydrothermal synthesis and luminescent properties of $(\mathrm{La}, \mathrm{Gd}) \mathrm{PO}_{4}: \mathrm{Tb}$ phosphors under VUV excitation," Materials Letters, vol. 61, no. 11-12, pp. 2416-2418, 2007.

[16] P. Morin, J. Rouchy, and Z. Kazei, "Magnetic and magnetoelastic properties in tetragonal $\mathrm{TbPO}_{4}$," Physical Review B, vol. 50, no. 17, pp. 12625-12634, 1994.

[17] C. Anderer, G. Hess, and H. G. Kahle, "Extensive studies on the low-temperature properties of $\mathrm{TbPO}_{4}$. II. Measurements of the Faraday rotation," Journal of Physics: Condensed Matter, vol. 5, no. 7, article 022, pp. 945-954, 1993.

[18] Z. Wang, Z. Quan, and J. Lin, "Remarkable changes in the optical properties of $\mathrm{CeO}_{2}$ nanocrystals induced by lanthanide ions doping," Inorganic Chemistry, vol. 46, no. 13, pp. 5237-5242, 2007.

[19] Z. L. Wang, J. H. Hao, H. L. W. Chan, W. T. Wong, and K. L. Wong, "A strategy to simultaneously realizing the cubicto-hexagonal phase transition and controlling small size of $\mathrm{NaYF}_{4}: \mathrm{Yb}^{3+}, \mathrm{Er}^{3+}$ nanocrystals for in-vitro cell imaging," Small, vol. 8, no. 12, pp. 1863-1868, 2012.

[20] J. Lü, T. Fan, J. N. Xie, and G. J. Chen, “Tunable luminescence and energy transfer of $\mathrm{TbPO}_{4}: \mathrm{Eu}^{3+}$ nanocrystals," Optics Communications, vol. 286, no. 12, pp. 221-223, 2013.

[21] L. H. Zhang, H. P. You, M. Yang, and Y. H. Song, "Facile one-pot synthesis and luminescence of hexagonal $\mathrm{TbPO}_{4} \cdot \mathrm{nH}_{2} \mathrm{O}$ hollow spheres," Materials Letters, vol. 67, no. 1, pp. 256-258, 2012.

[22] M. Yang, H. You, Y. Song et al., "Synthesis and luminescence properties of sheaflike $\mathrm{TbPO}_{4}$ hierarchical architectures with different phase structures," Journal of Physical Chemistry C, vol. 113, no. 47, pp. 20173-20177, 2009.

[23] X. D. Zhang and Y. Xie, "Recent advances in free-standing twodimensional crystals with atomic thickness: design, assembly and transfer strategies," Chemical Society Reviews, vol. 42, no. 21, pp. 8187-8199, 2013.

[24] J. Yang, C. Lin, Z. Wang, and J. Lin, " $\operatorname{In}(\mathrm{OH})_{3}$ and $\operatorname{In}_{2} \mathrm{O}_{3}$ nanorod bundles and spheres: microemulsion-mediated hydrothermal synthesis and luminescence properties," Inorganic Chemistry, vol. 45, no. 22, pp. 8973-8979, 2006.

[25] Z.-L. Wang, H. L. W. Chan, H.-L. Li, and J. H. Hao, "Highly efficient low-voltage cathodoluminescence of $\mathrm{LaF}_{3}: \mathrm{Ln}^{3+}$ ( $\mathrm{Ln}=$ $\left.\mathrm{Eu}^{3+}, \mathrm{Ce}^{3+}, \mathrm{Tb}^{3+}\right)$ spherical particles," Applied Physics Letters, vol. 93, no. 14, Article ID 141106, 2008.

[26] Z.-L. Wang, J. Hao, and H. L. W. Chan, "Light emission due to energy transfer from $\mathrm{Gd}^{3+}$ to $\mathrm{Eu}^{3+}$ ions in paramagnetic $\mathrm{NaGdF}_{4}: \mathrm{Eu}^{3+}$ submicrometer disks," Journal of the Electrochemical Society, vol. 157, no. 10, pp. J315-J318, 2010. 

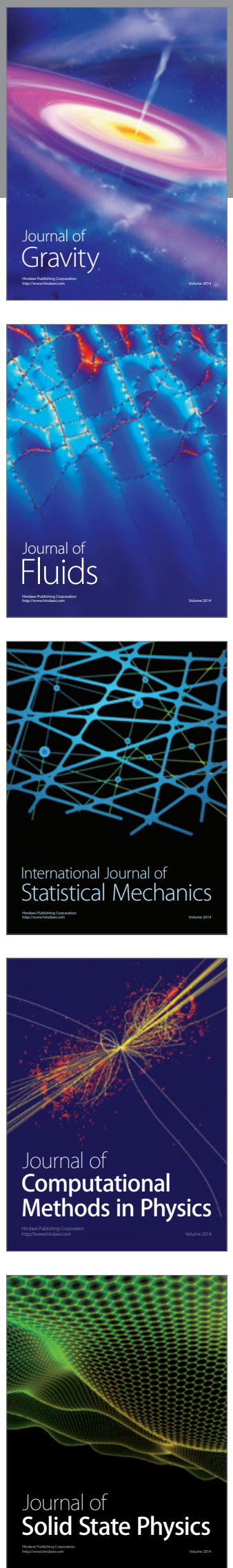

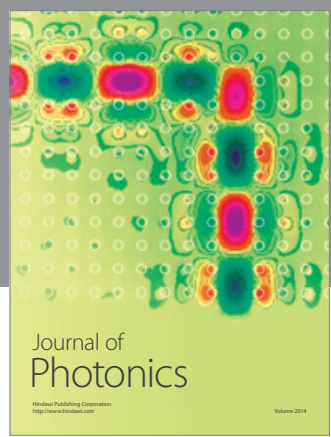

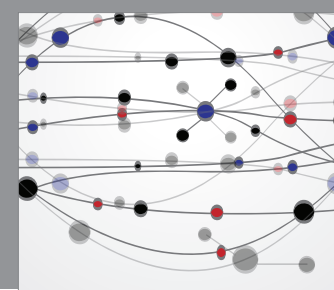

The Scientific World Journal

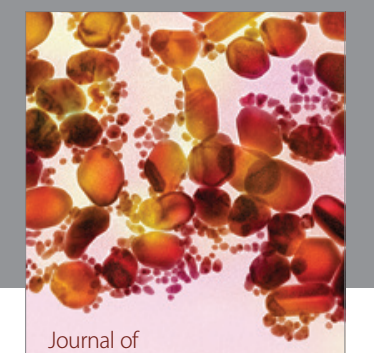

Soft Matter
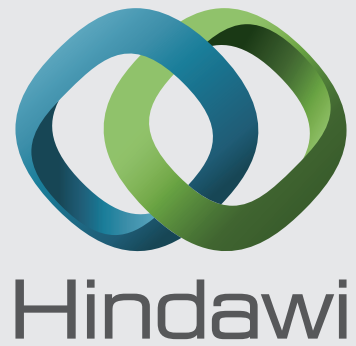

Submit your manuscripts at

http://www.hindawi.com
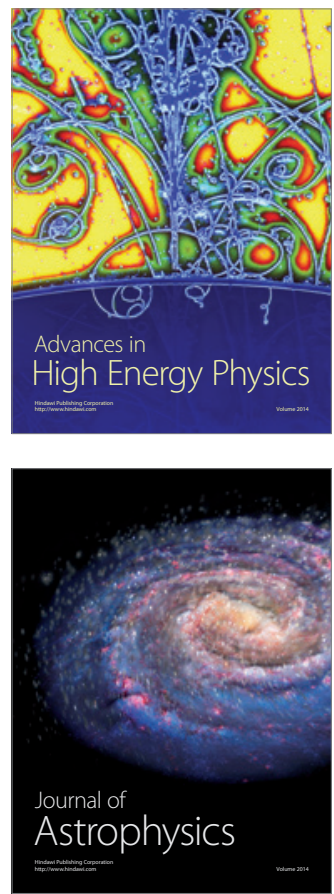
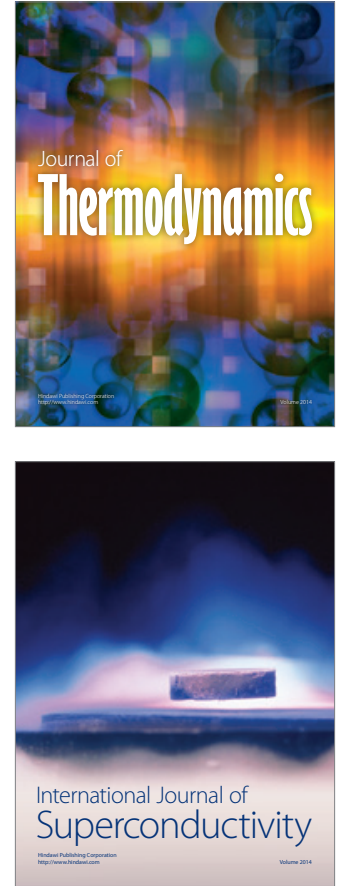
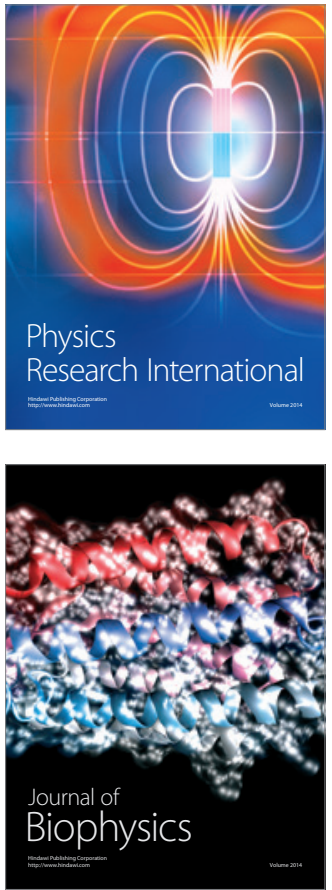
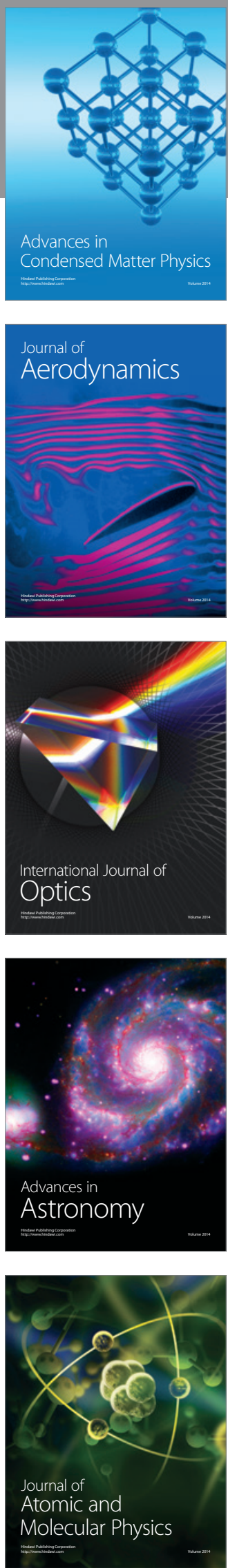